\title{
Difficulty Falling Asleep Scale
}

National Cancer Institute

\section{Source}

National Cancer Institute. Difficulty Falling Asleep Scale. NCI Thesaurus. Code C131957.

A scale for the subjective scoring of difficulty faling asleep that ranges from 0: No difficulty to 10: Didn't fall asleep. 